\title{
Hepatitis B Co - Infection in HIV AIDS Patients in Woldia, Ethiopia
}

\author{
Endeshaw Abatenh*, Amare Asmamaw, Lemelem Hiluf and Nebil Mohammed \\ Department of Biology, Woldia University, Ethiopia
}

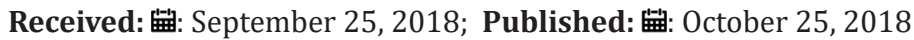

*Corresponding author: Endeshaw Abatenh, Woldia University, Faculty of Natural and Computational Science, Department of Biology, Woldia, Ethiopia

\begin{abstract}
Hepatitis B is one of liver infection resulting from the presence of viral agents. HIV infected individuals are more susceptible to hepatitis B viral infection as their disease progresses into AIDS. Now a day, Hepatitis B is present in HIV infected patients. The aim of this study was to investigate medical information and to get their perception regarding co-infection as well as to assess associated risk factors for Hepatitis B abnormalities among HIV positive patients in Woldia General Hospital, Ethiopia. The questionnaire form was filled up appropriately. They are also forward relevant characteristics. HIV-AIDS patients co-infected with Hepatitis B was studied. A total of 30 patients were included here. Different social groups were participated during in the time of the study. From the total study population, $46.7 \%$ (14) are males and 53.3\% (16) are females. They have a variety of personal characteristics. Most of the $53 \%$ were illiterate and $43.33 \%$ survive in agricultural practice. The major associated risk factors facilitate for co-infection were unprotected sexual habit, screening with a variety of pathogens, sharing unsterilized personal types of equipment and illegal drug use. The basic point of reason had both weak immune system and low CD4 cell count was commented from respondents. To solve the problem first, free from unsecured sexual intercourse who had already Hepatitis B. Second, sterilizing equipment's. Lastly, avoiding illegal drug usage. In overall patients should have to get a vaccine. Finally, they had a good common understanding of medical aspects.
\end{abstract}

Keywords: (HBV) Hepatitis B Virus; HIV (Human Immunodeficiency Virus); AIDS (Acquired Immuno Deficiency Syndrome); Co-Infection; Risk Factor

\section{Introduction}

Hepatitis B is a disease caused by the hepatitis B virus that attacks the liver. The virus is responsible for the lifelong liver infection, liver cirrhosis, liver cancer and liver failure and subsequent death. HBV is the major health problem in different parts of the world. It is potential for morbidity and mortality in HIV patients due to both share uniform way of transmission pattern then the possibility of coinfection leads to high/more chronic [1-4]. HIV AIDS patients are sensitive for opportunistic infection and co-infection especially in Hepatitis B virus [5]. The presence of hepatitis B virus (HBV) in patients infected by the human immunodeficiency virus (HIV) leads to a higher incidence of liver disorders due to persistence and recurrence of HBV infection [6]. HIV/AIDS is one of the most crucial public health challenges, particularly in the low and middle-income region. In Ethiopia, the rate of transmission is increased from time to time because of the recent development of casual attitude towards sex, degradation of traditional and indigenous value. There have been no published papers reported in our hospital. In addition to this, there is no studies were conducted regarding hepatitis B virus coinfection in HIV AIDS patients in Woldia town up to yet. Therefore, bearing this in mind this study was conducted. The aim of the research is: a) To know clinical sign and symptoms of HIV AIDS patients coinfected within the HBV.

b) To explore the associated risk factors of HIV AIDS patients coinfected within HBV.

c) To identify the major reason for exposing/ screening of HIV AIDS patients coinfected with an opportunistic infection.

d) To assess control and prevention mechanism for HIV positives not easily susceptible for HBV.

\section{Material and Methods}

\section{Description of the Study Area}

Semien Wollo (North Wollo) is one of 10 zones of the Amhara Region of northern Ethiopia. It is bordered on the south by Debub Wollo (South Wollo), on the west by Debub Gondar (South Gondar), on the north by Wag Hemra, on the northeast by Tigray Region, and on the east by Afar Region; part of its southern border is defined by the Mille River (Table 1). It is located 521 kilometers away from Addis Ababa. The global positioning system coordinates of Woldia in terms of latitude and longitude indicate that $11^{\circ} 49^{\prime} 59.99^{\prime \prime} \mathrm{N}$ 
and $39^{\circ} 40^{\prime} 59.99^{\prime \prime}$ E respectively (Figure 1). The elevation is 2,112 meter above sea level. Woldia has an estimated total population of
46,139 people. Out of this 23,000 are males and 23,139 are females [7].

Table 1: Associated risk factors HIV - AIDS patients co-infected with hepatitis B.

\begin{tabular}{|c|c|c|}
\hline Variable & Number (N) & Percentage $(\%)$ value \\
\hline Screening with the opportunistic infection & 2 & $6.66 \%$ \\
\hline Chewing chat, smoking cigarette and drinking alcohol & 2 & $6.66 \%$ \\
\hline Unprotected sexual intercourse with a single and multi-sexual partner & 5 & $16.66 \%$ \\
\hline $\begin{array}{l}\text { Abnormal and illegal drug use that is taking the drug over recommended } \\
\text { doze }\end{array}$ & 4 & $13.33 \%$ \\
\hline $\begin{array}{l}\text { Using and sharing unsterilized personal equipment's (contaminated } \\
\text { needles) for ear piercing and tattooing }\end{array}$ & 4 & $13.33 \%$ \\
\hline Vertical transmission & 2 & $6.66 \%$ \\
\hline Unsafe blood transfusion & 2 & $6.66 \%$ \\
\hline Malnutrition & 1 & $3.33 \%$ \\
\hline Low socioeconomic status & 1 & $3.33 \%$ \\
\hline Contacted with secreted body substances (compounds) together & 4 & $13.33 \%$ \\
\hline Immunity system destruction due to HIV from time to time & 3 & $10 \%$ \\
\hline
\end{tabular}

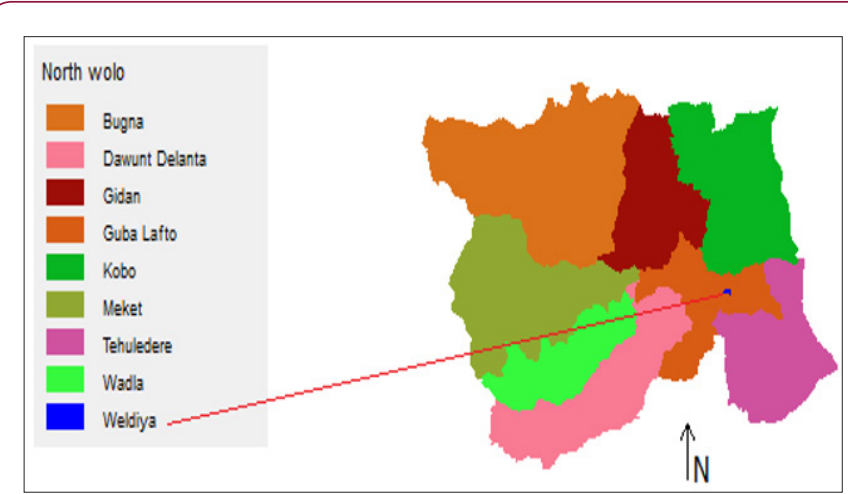

Figure 1: Map of study area.

\section{Sampling Technique}

Purposive sampling technique was applied and used for the selection and inclusion of representative HIV-AIDS patients coinfected with Hepatitis B, who already attended in Woldia General Hospital.

\section{Sample Size}

For this paper, 30 individuals or else informants were selected for the study of HIV patients co-infected with Hepatitis B. Due to financial constraints, lack of adequate resource and a shortage of study time interval the sample size become minimized.

\section{Study Population}

All necessary data were taken /acquired from patients visited in hospital and different social groups who inhabitants in the area (Figure 2) and (Table 2). HIV-positive individuals were seen at Hospital they actively participate. The subjects recruited for this study were confirmed HIV/AIDS patients, presenting with HBV complications. The duration of HIV/AIDS infection showed that those with prolonged AIDS. All HIV patients already tested for the presence of $\mathrm{HBV}$ and also the final screening result showed that positive.

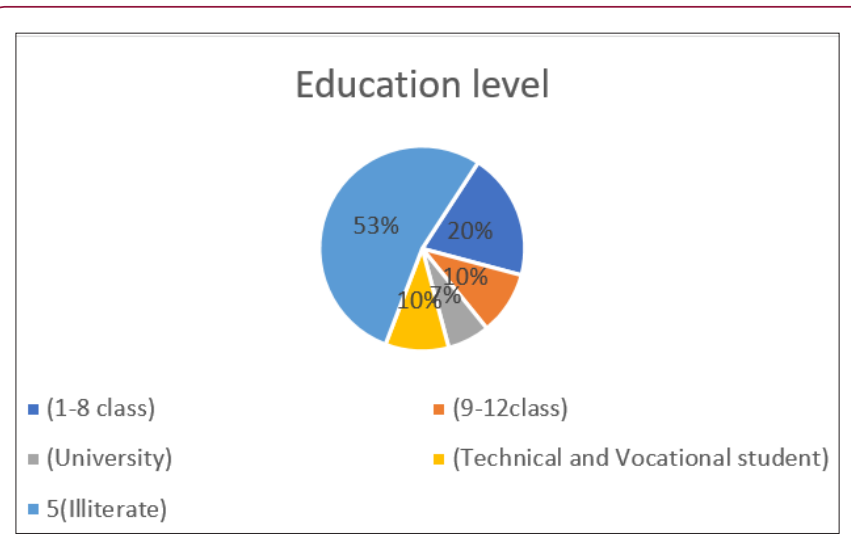

Figure 2: Education level of respondents.

Table 2: Sign and Symptoms for HIV ADIS patient's co infected with hepatitis $B$.

\begin{tabular}{|c|c|c|}
\hline Variable & Number(N) & $\begin{array}{c}\text { Percentage } \\
\text { (\%) value }\end{array}$ \\
\hline Body weight loss & 4 & $13.33 \%$ \\
\hline Color change of eye (jaundice) & 3 & $10 \%$ \\
\hline Variable body temperature & 1 & $3.33 \%$ \\
\hline Diarrhea & 2 & $6.66 \%$ \\
\hline $\begin{array}{c}\text { Right upper quadrant pain and pain in } \\
\text { liver body organ }\end{array}$ & 3 & $10 \%$ \\
\hline Vomiting & 1 & $3.33 \%$ \\
\hline Fever & 1 & $3.33 \%$ \\
\hline Chills & 1 & $3.33 \%$ \\
\hline Weakness of body and swelling part of & 4 & $13.33 \%$ \\
\hline body or tiredness & 2 & $6.66 \%$ \\
\hline Nausea & 2 & $6.66 \%$ \\
\hline Headache & & \\
\hline
\end{tabular}




\begin{tabular}{|c|c|c|}
\hline Loss of appetite & 1 & $3.33 \%$ \\
\hline $\begin{array}{c}\text { Enlargement of liver, cirrhosis and liver } \\
\text { cancer eventually develop }\end{array}$ & 4 & $13.33 \%$ \\
\hline
\end{tabular}

\section{Study Design}

A Hospital based cross-sectional study design was conducted among HIV AIDS patients who visited the hospital from January up to July 2015, in Woldia town, Ethiopia. The selection of Woldia town had been based on the accessibility, easy for transportation, a high number of people live together and the presence of a general hospital that provides health care for the society.

\section{Data Type and Data Source}

The mechanism of gathering data was accomplished/supported in qualitative data type. Furthermore, primary data were sourced/ obtained from respondents/hospitalized patients.

\section{Data Collection Technique}

The primary (demographic, socio-economical and epidemiological) data were collected directly from patients who will for the interview and forward enough information about the listed research objective. Focus group discussion was constructed. Then, participants were interviewed by using a semi-structured questionnaire, in a local Amharic next translate to the English language (Figure 3) and (Table 3). Open and closed-ended type questionnaire was prepared/developed and distributed to the study sample population. Finally, relevant medical and behavioral data were collected. All section of the questionnaire was pre-tested before finalization.

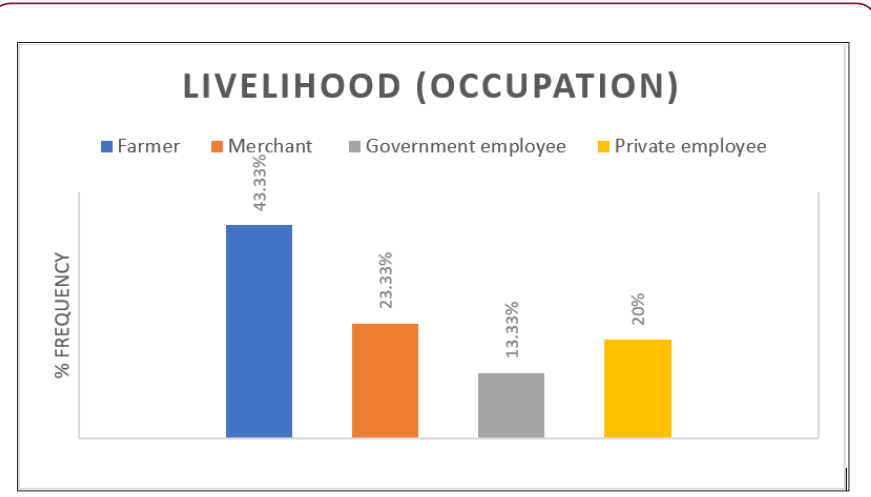

Figure 3: Livelihood of respondents.

Table 3: Prevention and control mechanism for HIV AIDS patient's not to be co-infected with hepatitis $B$.

\begin{tabular}{|c|c|c|}
\hline Variable & Number(N) & $\begin{array}{c}\text { Percentage } \\
\text { (\%) value }\end{array}$ \\
\hline $\begin{array}{c}\text { Avoiding blood and other body fluid } \\
\text { close contact with infected person }\end{array}$ & 3 & $10 \%$ \\
\hline $\begin{array}{c}\text { Keeping personal hygiene and } \\
\text { environmental sanitation }\end{array}$ & 3 & $10 \%$ \\
\hline Stopping excess alcohol consumption & 2 & $6.66 \%$ \\
\hline $\begin{array}{c}\text { Using a condom, introducing one to } \\
\text { one mechanism for sexual intercourse } \\
\text { or implement sexual abstinence }\end{array}$ & 4 & $13.33 \%$ \\
\hline Using wisely given drug by physicians & 5 & $16.66 \%$ \\
\hline
\end{tabular}

\begin{tabular}{|c|c|c|}
\hline $\begin{array}{c}\text { Sterilizing contaminated foodstuff } \\
\text { completely }\end{array}$ & 3 & $10 \%$ \\
\hline Do not share personal equipment's & 6 & $20 \%$ \\
\hline $\begin{array}{c}\text { Stopping the participation in sexual } \\
\text { intercourse with many infected } \\
\text { partner }\end{array}$ & 4 & $13.33 \%$ \\
\hline
\end{tabular}

\section{Statistical Analysis}

Data was checked for its completeness before the analysis was done. Then, all necessary data were organized, entered and analyzed by using SPSS V 20.0. Descriptive statistics (mean and percentages) method were used/applied to characterize study subjects. The way of presentation and interpretation of the data was made and explained in a form of a table, graph, pictogram and percentage value.

\section{Ethical Consideration}

Ethical clearance was taken from Woldia General Hospital medical directorate office. Full permission was allowed to conduct the research then all participants were informed about the objective and procedure profoundly. Privacy and confidentiality well maintained. Each questionnaire was numerically coded without any personal identification. Later, our consent result was presented to physicians working at the hospital to cheek up against the relevancy of clinical based data.

\section{Result}

\section{Socio-Demographic Profile (Characteristics) of Individ- uals}

A total of thirty study populations (potential candidates) are selected and clustered into five groups. One group at least hold ten study individuals. Then hot discussion lesson continued, and they also provide all necessary relevant response (characteristics). The research outcome indicated that out of the $46.7 \%$ (14) are males and $53.3 \%$ (16) are females. The mean age size of patients was $33 \pm 1$ years included here. The marital status of patients $36.66 \%$ (11) of the population is married, $46.66 \%$ (14) is single and also the remaining $16.66 \%$ (5) is divorce. Based on research finding, All HIV AIDS subjects are co-infected with HBV and they are used as a source of information. All respondents also have a common understanding about the causative agent which is already virus. Economic status of respondents on the basis of monthly and annually generated income $6.66 \%$ (2) participants are grouped in first class, 20\% (6) respondents are clustered in medium class and $73.33 \%$ (22) of individuals are found in third class (live in under poverty level).

The reason for co-infection within HBV based on informant consensus 20\% (6) were told us/ announced within brief description: lack of well-organized acquired and innate immunity system, 43.33\% (13) were explained white blood cells and CD4 cell gradually become very low. The last $36.66 \%$ (11) were forward the detailed explanation that HIV is developing immunity system problem which leads to immunity function become retarded. At that moment cannot effective in HBV prevention. 


\section{Discussion}

HBV infection had negative impacts on the history of HIV seropositive. Both HBV and HIV are viruses that share certain epidemiological characteristics such as risk populations and transmission routes. The risk of chronic hepatitis $B$ is higher in co-infected HIV patients. HIV/HBV co-infected patients showed worse clinical and immunological features [8]. The majority of the participants in the current study were women $(53.3 \%)$. The predominance of women in the present study outcome was correlated already reported in previous time [9]. The finding that HIV seropositivity leads to increased prevalence of HB. The prevalence of HB seropositivity increased with deteriorating immune status reflected by lower CD4+ cell counts. Increasing prevalence of HBeAg with worsening HIV-induced immunosuppression. Reasons for getting opportunistic infection also related to CD4 cell count decline gradually. This finding was consistent with other studies done on related title [9-11]

The main possible factors for co-infection rate leads (brings) to high: Smoking, blood transfusion, alcohol consumption, sharing razor for tattooing, injecting drug use, unsafe injection, unusual drug addiction, unsafe homo and hero-sexual habit (lifestyles), unsafe surgical history, tooth extraction and low CD4 count are baseline characteristics and also supported with many coherent studies in different place $[3,4,6,8,12-16]$. In the current study, all respondents have knowledge toward prevention practices on HBV. Responses to preventive/ protective measures are frequently washing hands, used protective instruments, sterilizing equipment's, disinfecting materials and participating in the vaccination program. This finding has resembled with the previous study from Northwest Ethiopia and India that reported a good knowledge of the study participants on HBV infection $[17,18]$. The present study survey showed that HBV-infected patients had different socio-demographic characteristics. Based on the finding of this study, major clinical manifestations such as fever, fatigue, loss of appetite, jaundice, rash, joint pain, and headache were confirmed with other papers also [19,20].

\section{Conclusion}

Hepatitis B is one of the leading causes of acute and chronic in HIV/ AIDS-infected patients in Woldia town. Thus, the patients can get immediate treatment and needs intensive care in order to prevent them from health devastation. Generally, in our study, many possible risk factors had explored and identified for respective/ contributive opportunistic infections.

\section{Recommendation}

Researchers should be initiated to do more investigation regarding sero- prevalence of HIV positive individuals. For North Wollo administrative zone to develop, provide and manage treatment options as well as creating public awareness campaign against HIV/AIDS and its opportunistic infections frequently.

\section{Acknowledgment}

The research paper submitted to the department of biology the partial fulfillment of requirements degree of science in Biology.
First, we would like to acknowledgment our God to support us who give the power and endurance to accomplish our goal. The second gratitude goes to our unique Miss Rahel Gebeyehu for her valuable critical comments and contractive advice. In the third place, we thank the Biological Science department head Mr. Mihretu Tarekegn to provide unrestricted supporting our work by different means. Finally, we would like to acknowledge the Woldia General Hospital Society for their excellent willingness and unfailing cooperation during the survey and we would like thanks to our interview informants and questionnaire respondent. We also would like to thank our family for their continuous support for our academic success and financial support.

\section{References}

1. Akosua Adom Agyeman, Richard Ofori Asenso (2016) Prevalence of HIV and hepatitis B Co-infection in Ghana: a systematic review and meta-analysis. AIDS Res Ther 13(23): 1-9.

2. Kranthi Kosaraju, Shashiraja Padukone, Indira Bairy (2011) Co-infection with hepatitis viruses among HIV-infected individuals at a tertiary care center in South India. Tropical Doctor 41(3): 170-171.

3. Nwako Okechukwu, Mbata Godwin, Ofondu Eugenia, Emeh Desmond, Obi Patrick (2013) The Seroprevalence of Hepatitis B Viral Infection in HIV Tested Positive Individuals in Owerri, Imo State, Nigeria. AIDS Clin Res 5(1): 1-4.

4. Manuela Arbune, Costinela Georgescu (2013) Characteristics of Hepatitis B Co-infection and Disease Evolution in HIV-Positive Paediatric Patients in Romania. Balkan Med J 30(3): 263-267.

5. Simnikiwe H Mayaphi, Theresa M Rossouw, Difuro P Masemola, Steve A S Olorunju, M Jeffrey Mphahlele, et al. (2012) HBV/HIV co-infection: The dynamics of HBV in South African patients with AIDS. S Afr Med J 102(3): 157-162.

6. Aline C Vieira, Maria RPA Tizzot, Vera LP Santos, Fernanda Bovo, Iara M (2015) Reason. Epidemiological analysis of serological markers of hepatitis B in HIV+ patients from Curitiba and metropolitan region. J Bras Patol Med Lab 51(1): 17-21.

7. (2007) Central Statistical Agency of Ethiopia, East Africa.

8. Monia Pugliaa, Cristina Stasia, Monica Da Frèa, Fabio Voller (2016) Prevalence and characteristics of HIV/HBV and HIV/HCV co-infections in Tuscany. Braz J infect dis 20(4): 330-334.

9. Michael O Iroezindu, Comfort A Daniyam, Oche O Agbaji, Ejiji S Isa, Edith N Okeke, et al. (2013). Prevalence of hepatitis B e antigen among human immunodeficiency virus and hepatitis B virus co-infected patients in Jos, Nigeria. J Infect Dev Ctries 7(12): 951-959.

10. Philippa C Matthews, Apostolos Beloukas, Amna Malik, Jonathan M Carlson, Pieter Jooste, et al. (2015). Prevalence and Characteristics of Hepatitis B Virus (HBV) Co-infection among HIV-Positive Women in South Africa and Botswana. PLOS ONE 10(7): 1-11.

11. Jayeeta Sarkar, Debraj Saha, Bhaswati Bandyopadhyay, Bibhuti Saha, Deepika Kedia, et al. (2016) Baseline characteristics of HIV \& hepatitis B virus (HIV/HBV) co-infected patients from Kolkata, India. Indian J Med Res 143(5): 636-642.

12. Bayeh Abera, Yohanes Zenebe, Wondemagegn Mulu, Mulugeta Kibret, Getachew Kahsu (2014) Seroprevalence of hepatitis B and C viruses and risk factors in HIV infected children at the felgehiwot referral hospital, Ethiopia. BMC Research Notes 7(838): 1-6.

13.SD Gyar, P Agbo, CR Reuben (2014) Assessment of Hepatitis B Coinfection among HIV/AIDS patients Attending Antiretroviral Therapy (ART) Clinic in Garaku, central Nigeria. Research Journal of microbiology 9(5): 232-238.

14. Letebrhan Weldemhret, Tsehaye Asmelash, Rashmi Belodu, Dawit Gebreegziabiher (2016) Sero-prevalence of HBV and associated risk 
factors among HIV positive individuals attending ART clinic at Mekelle hospital, Tigray, Northern Ethiopia. AIDS Res Ther 13(6): 1-7.

15. Bùi V Huy, Kanxay Vernavong, Nguy, VsnKính (2014) HBV and HCV Coinfection among HIV/AIDS Patients in the National Hospital of Tropical Diseases, Vietnam. AIDS Research and Treatment.

16. Mohammad Ali Davarpanah, Nursing Motazedian, Ebrahim Fallahzadeh, Maryam Rasti, Hashem Rahmati, Nadia Motazedian (2015) Hepatitis B Virus Infection Serology and the Associated Risk Factors among Patients with HIV in Shiraz, Iran. Shiraz E-Med J 16(4): 1-5.

17. Abdnur Abdela, Berhanu Woldu, Kassahun Haile, Biniam Mathewos, Tekalign Deressa (2016) Assessment of knowledge, attitudes and practices toward prevention of hepatitis $B$ virus infection among
ISSN: 2574-1241

DOI: 10.26717/BJSTR.2018.10.001949

Endeshaw Abatenh. Biomed J Sci \& Tech Res

This work is licensed under Creative Commons Attribution 4.0 License

Submission Link: https://biomedres.us/submit-manuscript.php students of medicine and health sciences in Northwest Ethiopia. BMC Res Notes 9(410): 1-7.

18. Vishal Malhotra, Sakshi Kaura, Harmesh Sharma (2018) Knowledge, Attitude and Practices about Hepatitis B and Infection Control Measures among Dental Students in Patiala. Journal of Dental and Allied Sciences 6(2): 65-69.

19. Yong Tao Han, Chao Sun, Cai-Xia Liu, Shuang-Shuang Xie, Di Xiao, et al. (2014) Clinical features and outcome of acute hepatitis B in pregnancy. BMC Infectious Diseases 14(368): 1-7.

20.Xiaohong Chen, Chengtao Fu, Jia Liu, Lei Shan, Chenglin Liu (2015) Recent epidemiological and clinical features of acute hepatitis B in a single center of China. Int J Clin Exp Med 8(9): 16652-16657.

BIOMEDICAL
RESEARCHES $\quad \begin{aligned} & \text { Assets of Publishing with us } \\ & \text { - Global archiving of articles }\end{aligned}$

